\title{
Benchmarking pain outcomes for children with sickle cell disease hospitalized in a tertiary referral pediatric hospital
}

\author{
Abi Vijenthira BHSc ${ }^{1}$, Jennifer Stinson RN PhD CPNP1,2, Jeremy Friedman MD MBChB FRCPC 3,4 , \\ Lori Palozzi RN(EC) MScN NP-Peds ${ }^{5}$, Anna Taddio PhD ${ }^{1,6}$, Dennis Scolnik MBChB FRCPC 1,4,7, \\ Charles Victor $\mathrm{MSC}^{8}$, Melanie Kirby-Allen MD ${ }^{4,9}$, Fiona Campbell BSc MD FRCA ${ }^{5,10}$
}

\begin{abstract}
A Vijenthira, J Stinson, J Friedman, et al. Benchmarking pain outcomes for children with sickle cell disease hospitalized in a tertiary referral pediatric hospital. Pain Res Manage 2012;17(4):291-296.
\end{abstract}

BACKGROUND: Painful vaso-occlusive crisis (VOC) is the most common reason for hospitalization in children with sickle cell disease.

OBJECTIVE: To benchmark pain outcomes in sickle cell disease, including process outcomes (eg, pain assessment and documentation practices, pain management interventions) and clinical outcomes (eg, pain intensity over hospital stay), to identify areas for improvement.

METHODS: A retrospective study was conducted on electronic charts of children hospitalized with a primary diagnosis of VOC between July 2007 and August 2008.

RESULTS: A convenience sample of 50 admissions was used. In terms of clinical outcomes, patients presented to the emergency department with an initial median pain intensity of $9 / 10$ (interquartile range $8 / 10$ to $10 / 10$ ). Forty-three per cent had not used opioids for pain relief at home. The mean ( \pm SD) length of stay was $4.0 \pm 2.3$ days. For most patients, median scores for highest daily pain intensity remained moderate to high throughout hospitalization, although scores did decrease significantly per day of hospitalization. In terms of process outcomes, pain intensity was assessed according to hospital standards on $25 \%$ of days in both the emergency department and the ward. There was no discrepancy between prescribed and administered opioid doses and medication use. In 95\% of cases, strong opioid use was in a subtherapeutic or low therapeutic dosage range.

CONCLUSIONS: The results showed three areas to target for improvement: improved pain assessment and documentation using valid pain tools; more aggressive multimodal management for peak VOC pain; and better education and support for pain management at home. Further studies are required to evaluate optimal pain treatment practices.

Key Words: Children; Pain assessment; Pain management; Sickle cell disease

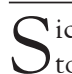
ickle cell disease (SCD) is the most prevalent hereditary hematological disease worldwide, and affects between 72,000 and 98,000 individuals in the United States alone (1). The hallmark of this condition is recurrent episodes of acute severe pain due to vasoocclusive crisis (VOC). VOC is caused by ischemic tissue injury resulting from occlusion of blood vessels by sickled erythrocytes. Painful VOC accounts for $79 \%$ to $91 \%$ of emergency room visits and $59 \%$ to $68 \%$ of hospitalizations in patients with SCD (2).

The pain of SCD is extremely variable and unpredictable in onset, location, character, intensity and duration, and has been described as worse than postoperative pain and as intense as terminal cancer pain (3). VOC has been shown to significantly impact
Établir des normes de références à partir des issues

de la douleur chez des enfants ayant une drépanocytose et qui sont hospitalisés dans un hôpital pédiatrique de soins tertiaires raison pour laquelle les enfants atteints de drépanocytose sont hospitalisés. OBJECTIF : Établir des normes de référence à partir des issues de la douleur en cas de drépanocytose, y compris les résultats des processus (p. ex., évaluation de la douleur et pratiques de consignation, interventions de prise en charge de la douleur) et les issues cliniques (p. ex., intensité de la douleur pendant l'hospitalisation), afin de déterminer les secteurs à améliorer.

MÉTHODOLOGIE : Les chercheurs ont procédé à l'étude des dossiers électroniques d'enfants hospitalisés en raison d'un diagnostic primaire de CVO entre juillet 2007 et août 2008.

RÉSULTATS : Les chercheurs ont utilisé un échantillon de commodité de 50 admissions. Pour ce qui est des issues cliniques, les patients arrivaient à l'urgence aux prises avec une intensité de douleur médiane de 9/10 (plage interquartile de 8/10 à 10/10). Quarante-trois pour cent d'entre eux n'avaient pas utilisé d'opiö̈des pour soulager leur douleur à la maison. Ils étaient hospitalisés pendant une période moyenne $( \pm E ́ T)$ de 4,0 $\pm 2,3$ jours. Pour la plupart des patients, les indices médians d'intensité maximale de la douleur quotidienne demeuraient modérés à élevés tout au long de l'hospitalisation, mais ils diminuaient considérablement avec chaque nouveau jour d'hospitalisation. Sur le plan des résultats des processus, les chercheurs ont évalué l'intensité de la douleur d'après les normes hospitalières, soit $25 \%$ des jours à l'urgence et dans les unités. Il n'y avait pas d'écart entre les doses d'opioïdes prescrites, celles qui étaient administrées et l'usage des médicaments. Dans 95 \% des cas, un fort usage d'opioïde se situait dans une plage de posologie sous-thérapeutique ou peu élevée.

CONCLUSIONS : Les résultats révèlent trois secteurs d'amélioration à cibler : améliorer et étayer l'évaluation de la douleur au moyen d'outils de douleur valides, assurer une prise en charge multimodale plus dynamique lors des douleurs de pointe des $\mathrm{CVO}$ et mieux enseigner et soutenir la prise en charge de la douleur au domicile. Il faudra mener d'autres études pour évaluer les pratiques thérapeutiques optimales pour soulager la douleur.

children's health-related quality of life (4). Management of painful episodes is multifaceted and includes pharmacological, physical and psychological strategies, in addition to treatment of the underlying causes (eg, infection) or other complications. Pain should be treated as early and aggressively as possible because acute and persistent pain can result in significant morbidity $(5,6)$. The successful management of VOC pain includes titration of medications until adequate control is achieved $(7,8)$.

Various pain guidelines have been developed that advocate aggressive pain management during the first two to three days of hospitalization for painful VOC $(7,8)$. Despite these efforts, research knowledge on acute pain in hospitalized children with SCD is not effectively

${ }^{1}$ Child Health Evaluative Sciences, The Hospital for Sick Children; ${ }^{2}$ Lawrence S Bloomberg Faculty of Nursing, University of Toronto;

${ }^{3}$ Department of Paediatric Medicine, The Hospital for Sick Children; ${ }^{4}$ Department of Paediatrics, University of Toronto; ${ }^{5}$ Department of

Anaesthesia and Pain Medicine, The Hospital for Sick Children; ${ }^{6}$ Leslie Dan Faculty of Pharmacy, University of Toronto; ${ }^{7}$ Department of

Paediatric Emergency Medicine, The Hospital for Sick Children; ${ }^{8}$ Institute for Clinical Evaluative Sciences; ${ }^{9}$ Department of Haematology/

Oncology, The Hospital for Sick Children; ${ }^{10}$ Department of Anaesthesia, University of Toronto, Toronto, Ontario

Correspondence: Dr Jennifer Stinson, Child Health Evaluative Sciences, Research Institute, The Hospital for Sick Children, 555 University

Avenue, Toronto, Ontario M5G 1X8. Telephone 416-813-7654 ext 4514, fax 416-813-2143, e-mail jennifer.stinson@sickkids.ca 
translated into everyday practice. Results from several studies since these guidelines were published demonstrate that adequate pain relief is not being achieved during hospitalization in children with VOC pain (9-13), and children often received suboptimal doses of analgesics (10).

Given the body of evidence suggesting inadequate treatment, and the presence of physical and psychosocial consequences of unrelieved pain in this population, it is desirable to audit current practice, identify areas to target for improvement and provide a benchmark with which to evaluate the effectiveness of future interventions in children with SCD. The purpose of the present study was to benchmark pain outcomes including process outcomes (eg, pain assessment and documentation practice, pain management interventions) and clinical outcomes (eg, pain intensity over hospital stay).

\section{Participants and settings}

\section{METHODS}

Ethics approval was obtained from the institutional review board. All children admitted to a large university-affiliated pediatric tertiary care centre that serves metropolitan Toronto and central and northern Ontario with a primary diagnosis of pain due to a VOC between July 28, 2007, and August 26, 2008, were eligible. A secondary diagnosis in addition to VOC was permissible because these admissions still primarily involved pain management. If a patient was admitted more than once during this time period, only their first admission was eligible for inclusion. Patients with $S \beta$-plus thalassemia were excluded because their pain course is significantly less severe than that of other sickle cell types.

\section{Procedure}

A retrospective cohort study was conducted on electronic patient charts (EPCs) of eligible children with SCD admitted to the general pediatrics department. A Pain Audit Tool was used to extract information from the EPCs. The tool had been successfully used in two previous hospital-wide pain audits $(14,15)$. It was modified to be more specific to patients with SCD. Research assistants trained by the primary study investigator (JS) used the Pain Audit Tool to extract demographic and outcome data from the EPCs (a copy of this tool is available from the corresponding author).

\footnotetext{
Measures

Initial presentation to the emergency department: Information was collected regarding patients' initial pain intensity scores, the anatomical location of pain and medications taken for pain before arriving at the emergency department (ED).

Pain process outcomes: Pain intensity documentation practices: According to hospital pain assessment policy, pain should be assessed at the ED visit, on admission and then a minimum of once per shift by the nurse (16). However, if pain intensity scores are $\geq 4 / 10$ on the Numerical Rating Scale and/or the Face, Legs, Activity, Cry, Consolability scale, or at least medium pain on the Verbal Rating Scale, a pain management intervention should occur, and pain should be reassessed within $1 \mathrm{~h}$ (16). Reassessment should continue every $4 \mathrm{~h}$ or more often until the pain relief goal is achieved. For the purpose of the present study, a pain intensity of $<4 / 10$ or 'a little' was considered the pain relief goal. Documentation practices were determined on a $24 \mathrm{~h}$ daily basis beginning from time of admission to either the ED or the ward, by comparing patients' charts with these guidelines.

Pain management interventions: Using the Pain Audit Tool, information was extracted regarding medications used at home before admission, medications prescribed and administered during hospital stay, and physical and psychological interventions. Because a wide variety of opioids can be administered (via different routes) to patients, opioid medication doses were converted to intravenous morphine equivalents using hospital guidelines (17) to compare prescribed versus administered opioids.
}

Medication Quantification Scale: The Medication Quantification Scale (MQS) was used to quantify total medication use on the basis of pharmacological classification and dosage level (10). MQS scores provide a quantitative index of total medication usage suitable for statistical analysis, and scores over time show changes in treatment. The MQS is a validated tool (18), which has previously been adapted for use in children with SCD (10). MQS scoring involves two categories: medication classification and dosage level (10). Dosage ranges were obtained from the hospital dosage guidelines (19). Strong opioids were converted to intravenous morphine equivalents before assigning the dosage level score. MQS scores were calculated on a $24 \mathrm{~h}$ basis, beginning at time of admission to the ED. Scores were calculated for both prescribed and administered medications.

Clinical pain outcomes: Pain intensity assessment: Pain intensity was indicated in the charts using an 11-point Numerical Rating Scale, the Verbal Rating Scale, or the Face, Legs, Activity, Cry, Consolability scale pain assessment tool, depending on the child's age and cognitive stage. From these pain intensity scores, highest daily pain intensity and lowest daily pain intensity were determined on a $24 \mathrm{~h}$ daily basis beginning at time of admission to the ED.

\section{Statistics}

Data were analysed using SPSS version 17.0 (IBM Corporation, USA) (20). Descriptive statistics were used to summarize the data. Means and ranges are reported when the data had a Gaussian distribution, and medians and interquartile ranges (IQRs) are reported when the data had a non-Gaussian distribution (eg, pain intensity scores during hospitalization). To compare the ED versus the ward, or prescribed versus administered medication, Student's $t$ tests or Wilcoxon signedrank tests were used depending on whether data had a Gaussian distribution. A two-sided $\mathrm{P}<0.05$ was considered to be statistically significant.

Longitudinal data analysis using the random effects model was used to estimate regression coefficients ( $y$-intercepts and slopes) for MQS, peak pain and least pain data. Y-intercepts represent scores on the day of entry to the hospital. The slopes $(\beta)$ represent the amount of change in scores during the length of stay (from day 1 to day of discharge). A $\mathrm{P}<0.05$ indicates a slope $\beta$ that is significantly different from 0 (null $\mathrm{H}_{0}: \beta=0$ ) and represents either a significant increase (positive slope) or decrease (negative slope) in values over time. A $\mathrm{P}>0.05$ indicates a slope that is not significantly different from 0 and represents no change in scores over time.

Generalized estimating equations were used to model receipt of pain assessment onto location (ED versus ward) and time while controlling for age. Generalized estimating equations were used to account for the lack of independence in the outcome measurements (ie, the same children are measured at multiple time points both in the ED and the ward). When conducting longitudinal analysis, one must define the covariance structure (ie, how do the measurements correlate within individuals). An autoregressive covariance structure was assumed, which makes the assumption that measurements closer in time are more highly correlated than measurements further apart in time.

\section{Sample characteristics}

\section{RESULTS}

A patient flow diagram of patients included and excluded from the audit is presented in Figure 1. A convenience sample of 50 patients was used. Characteristics of the sample are summarized in Table 1. Dates of admission ranged from July 28, 2007, to April 26, 2008.

\section{Initial presentation to the ED}

Patients presented to the ED with an initial median pain intensity of $9 / 10$ (IQR 8/10 to 10/10). Patients most commonly experienced pain in one location (51\%). The most frequent location of pain was the back (41\%) and leg (37\%), although location was variable, including chest (33\%), abdomen (22\%) and arm (12\%). The least commonly reported locations included the head (2\%), hip (2\%), ankle (2\%) and knee (2\%). 


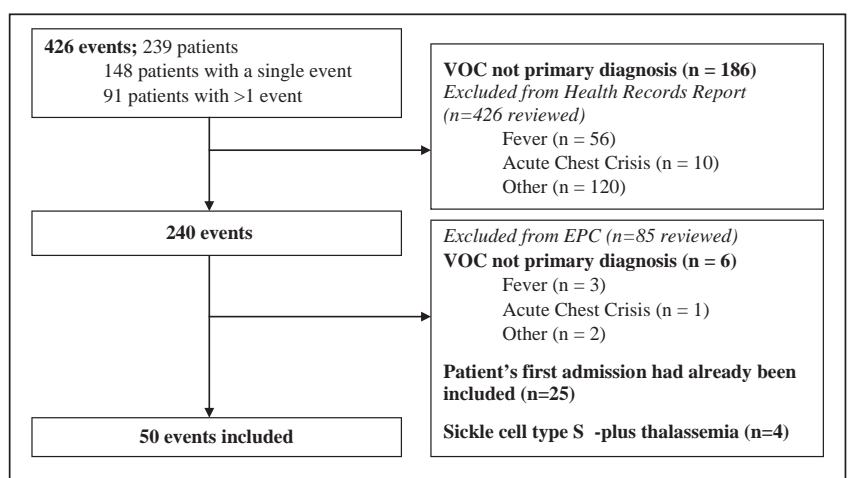

Figure 1) Patient record flow. EPC Electronic patient charts; VOC Vasoocclusive crisis

Nearly one-half of the patients (43\%) had not taken opioids for pain relief at home before arriving to the ED; $27 \%$ had taken acetaminophen and/or nonsteroidal anti-inflammatory drugs, and 16\% had not taken any analgesic medications at home. The other $57 \%$ of patients had taken opioids or a combination of opioids and acetaminophen/nonsteroidal anti-inflammatory drugs.

\section{Pain process outcomes}

Pain intensity documentation practices: Hospital standards for pain intensity documentation were met on $25 \%$ of days in the ED and $25 \%$ of days in the ward. Patients were equally as likely to be assessed for pain according to standards if they were in the ED compared with the ward (OR 0.88 [95\% CI 0.40 to 1.91]; $\mathrm{P}=0.74$ ). There was no significant effect of age on likelihood of meeting standards for pain assessment (OR 0.96 [95\% CI 0.80 to 1.14$] ; \mathrm{P}=0.64$ ). Finally, time in the ward also did not have a significant effect on meeting these standards (OR 1.00 [95\% CI 0.94 to 1.08]; P=0.91).

Pain management interventions: Medication usage: On the day of admission, the most frequently prescribed medications were morphine (94\%), acetaminophen (72\%) and ibuprofen $(40 \%) ; 22 \%$ of patients were prescribed a combination of all three. Other prescribed analgesics included codeine $(24 \%)$, ketorolac $(8 \%)$ and hydromorphone $(6 \%)$. Table 2 lists the dosage ranges of analgesic medications used throughout the hospital stay.

Morphine was the most frequently prescribed and administered medication, and was administered on $73 \%$ of days. The mean prescribed dose of intravenous morphine equivalent opioids was similar to the dose administered $(0.023 \pm 0.012 \mathrm{mg} / \mathrm{kg} / \mathrm{h}$ versus $0.022 \pm 0.012 \mathrm{mg} / \mathrm{kg} / \mathrm{h}[95 \%$ CI -0.0001 to 0.002 ]; $\mathrm{P}=0.08$ ).

Before hospital admission, $46 \%$ of patients were taking codeine alone, or a combination of codeine and another analgesic medication. In total, $65 \%$ of patients receiving oral opioids during their hospital stay received codeine and $48 \%$ were prescribed codeine at discharge.

In cases of constipation, nausea and pruritus, adverse effect medications, including lactulose, ondansetron, dimenhydrinate and diphenhydramine, were given. During their hospital stay, $40 \%$ of patients received medication for constipation, $18 \%$ received medication for nausea and $16 \%$ received medication for pruritus.

MQS scores: Figure 2 illustrates daily MQS scores over the length of the hospital stay. The mean prescribed MQS score on the first day of admission was $19.8 \pm 7.1$. Scores decreased significantly by $1.1 \pm 0.3$ per day of hospitalization $(\mathrm{P}<0.001)$. The mean administered MQS score on the first day was $17.8 \pm 6.3$, and scores decreased by $0.8 \pm 0.3$ per day $(\mathrm{P}<0.001)$. Prescribed and administered MQS scores were significantly and strongly associated $(\mathrm{P}<0.001, \mathrm{r}=0.81)$

There were also significant variations among participants in their prescribed and administered MQS score trajectories over time $(\mathrm{P}<0.001$ for both trajectories). This indicates that there was no consistent pattern in patients' medication usage during their hospital stay. For example, some patients' medication usage may have decreased
TABLE 1

Characteristics of patient sample $(n=50)$

\begin{tabular}{lc}
\hline Characteristic & \\
\hline Age, years, mean \pm SD (range) & $10.0 \pm 5.3(0.6-17.6)$ \\
Weight, kg, mean \pm SD (range) & $34.4 \pm 17.0(7.4-69.1)$ \\
Female, $\mathrm{n}(\%)$ & $31(62)$ \\
Hemoglobin phenotype, $\mathrm{n}(\%)$ & \\
$\mathrm{SS}$ & $43(86)$ \\
$\mathrm{SC}$ & $6(12)$ \\
$\mathrm{S} \beta$-negative thalassemia & $1(2)$ \\
Hospital visits* & \\
ED-only visits related to pain, median (IQR) & $0(0-1.25)$ \\
Sickle cell clinic visits related to pain, median (IQR) & $2(1-3)$ \\
Hospital admissions related to VOC pain, & $2.8 \pm 1.9(0-8)$ \\
$\quad$ mean \pm SD (range) & \\
Total number of days in hospital for VOC pain, & $8(4-14.5)$ \\
$\quad$ median (IQR) & \\
Diagnosis, $\mathrm{n}(\%)$ & \\
VOC & $40(80)$ \\
VOC + fever & $6(12)$ \\
VOC + chest crisis & $2(4)$ \\
VOC + other & $2(4)$ \\
Initial pain intensity rating, median (IQR) & $9(8-10)$ \\
Length of stay, days & \\
Length of stay in ED, median (IQR) & \\
Length of stay in ward, mean \pm SD (range) & $3.4 \pm 2.4(0-9.0)$ \\
Total length of stay, mean \pm SD (range) & $4.0 \pm 2.3(0.7-9.5)$ \\
\hline
\end{tabular}

*July 28, 2007, to August 26, 2008. ED Emergency department; IQR Interquartile range; VOC Vaso-occlusive crisis

TABLE 2

Medication Quantification Scale dosage ranges for each day that analgesic medications were prescribed to patients

\begin{tabular}{lccccc}
\hline & Days & \multicolumn{4}{c}{ Therapeutic range, \% } \\
\cline { 3 - 6 } Medication & prescribed, & Sub & Low & High & Supra \\
\hline Acetaminophen & 130 & 2 & 25 & 62 & 12 \\
Ibuprofen & 93 & - & 16 & 76 & 8 \\
Naproxen & 16 & 81 & 19 & - & - \\
Ketorolac & 25 & 48 & 36 & 16 & - \\
Codeine & 26 & - & 12 & 65 & 23 \\
Strong opioids & 182 & 7 & 88 & 5 & - \\
Not via PCA & 165 & 7 & 89 & 4 & - \\
Via PCA & 17 & 6 & 76 & 18 & - \\
\hline
\end{tabular}

PCA Patient-controlled analgesia

greatly, while others' usage may have decreased a little, stayed the same or even increased over time.

Physical pain management strategies: Physical interventions, which include providing hot packs or blankets, were not well documented in either the ED or the ward (20\% and $40 \%$ of cases, respectively). The most common physical intervention was the use of a hot pack, which was used in $73 \%$ of cases in the ED and $96 \%$ of cases in the ward.

Psychological pain management strategies: Documented psychological strategies consisted of types of distraction. These were reported for $12 \%$ of patients in the ED and $77 \%$ in the ward. The most commonly reported strategy was distraction by watching television or a movie (37\% of reports).

Clinical pain outcomes

Pain intensity assessment: Pain intensity decreased significantly from an initial median score of $9 / 10$ (IQR $8 / 10$ to $10 / 10$ ) to a median of $6 / 10$ (IQR 3/10 to 7/10) when patients were transferred to the ward $(\mathrm{P}<0.001)$, and to a median of 0 on discharge (IQR $0 / 10$ to $4 / 10)(\mathrm{P}<0.001)$. 


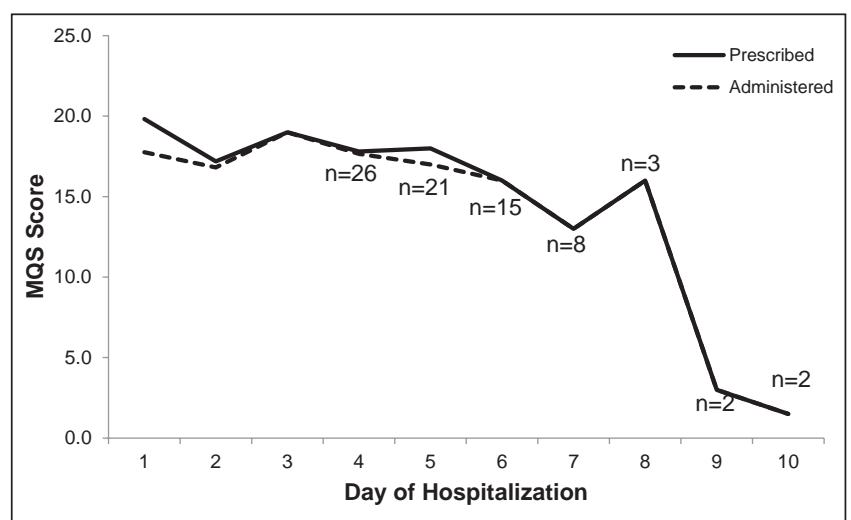

Figure 2) Prescribed and administered Medication Quantification Scale (MQS) scores per day of hospital stay. $n$ denotes number of patients remaining in hospital

For most patients, daily peak pain intensity remained moderate (pain score from $4 / 10$ to 6/10) to severe (pain score from $7 / 10$ to $10 / 10$ ) throughout the entire stay (Figure 3). However, peak pain intensity decreased significantly by an average of $1.0 \pm 0.2$ points per day of hospitalization $(\mathrm{P}<0.001)$. Daily least pain intensity also decreased significantly by $0.5 \pm 0.1$ points per day $(\mathrm{P}<0.001)$. However, there were significant variations in the pain intensity trajectories across time for participants, for both peak and least pain intensity $(\mathrm{P}<0.001$ for both). This indicates that there was no consistent pattern among patients in their peak and least pain intensity ratings throughout hospitalization. For example, some patients' pain intensity ratings may have decreased greatly, while others' intensity ratings may have decreased somewhat, stayed the same or even increased over time.

\section{DISCUSSION}

The present study audited current practice in VOC management to identify areas to target for improvement and provide a benchmark from which to evaluate future interventions in children with SCD at our centre. We described pain outcomes including process outcomes (eg, pain assessment and documentation practice, pain management interventions) and clinical outcomes (eg, pain intensity over hospital stay). The process outcomes helped to identify several areas to target for improvement and the clinical outcomes enabled us to learn more about the pain experience of children hospitalized for VOC.

\section{Process outcomes}

Pain intensity documentation practices: Pain assessment is necessary to titrate treatment to effect. Due to the retrospective nature of the present study, it is unclear whether pain intensity was being assessed and not recorded, or whether pain was not assessed at all. In either case, documentation is needed to visually track and communicate progression of pain to health care providers. Our findings show poor pain intensity documentation, especially in the ED, where $24 \%$ of patients had no documentation after triage. This is not just a problem with SCD patients, but also with other pediatric pain problems presenting to EDs. For example, of 24,707 visits to pediatric EDs in the United States, $55.5 \%$ had no documented pain scores (21). It is important to determine ways to improve pain documentation. In an adult ED setting, an educational intervention improved documentation from $72 \%$ to $94 \%$ (22). Studies are needed to pilot and assess the effectiveness of educational interventions plus audit and/or feedback practices on pain assessment and documentation practices in pediatric ED and ward settings, specifically in sickle cell populations. These studies should also investigate whether improved documentation practices have an effect on improving pain outcomes.

Pain management interventions: First, home pain management needs improvement in this population. Children arrived to the ED with severe pain intensity, yet a substantial number (43\%) had not received opioid medication at home, and $16 \%$ had not taken any pain

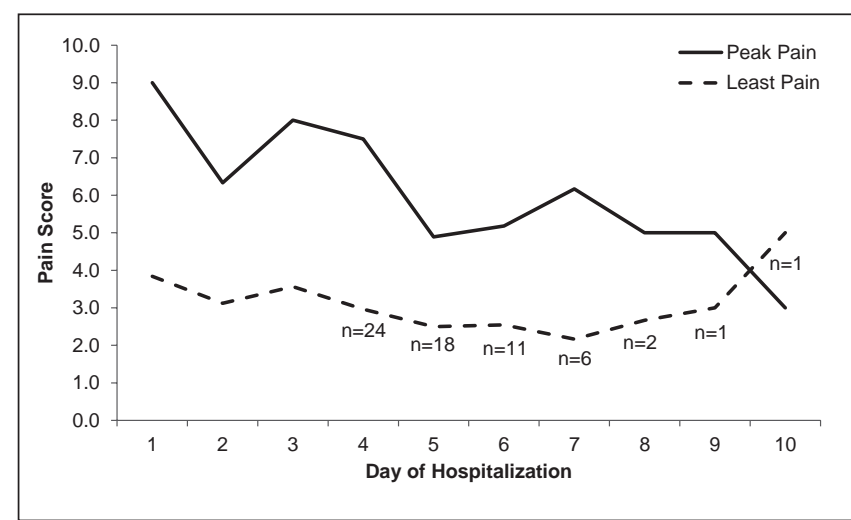

Figure 3) Daily peak and least pain intensity throughout hospitalization. $n$ denotes number of patients remaining in hospital

medications at all. These results are consistent with a previous study of home pain management for SCD (23), which suggested that poor management may be related to patient and parental concerns about the use of opioids. There are also other factors that could influence poor pain management, such as cultural values, access to prescriptions, and values and expectations toward pain by families and health care professionals. Some of these factors can be addressed by comprehensive education strategies for families about the need to aggressively manage pain at home. For example, at our hospital, we have begun to provide families with pain management information pamphlets and tracking forms. We also began an annual pain education day for children and families affected by SCD in 2010. Further studies are needed to determine the effects of home management interventions, such as improved education, on pain intensity scores and hospitalization rates. However, we also need to learn more about the factors influencing poor pain management in the home setting, to better address them. Qualitative studies may be helpful in this regard.

Second, pain remained undertreated throughout the hospital stay. Unlike previous studies (11), we found a close correlation between prescribed and administered medications, likely because most of our patients were on continuous infusions and boluses rather than on patient-controlled analgesia (as in previous studies). However, despite this close correlation, peak pain intensity remained moderate to severe throughout their stay for most patients, and MQS scores showed that children received subtherapeutic and low therapeutic dosages of many medications, including strong opioids and other analgesics such as naproxen and ketorolac. This finding suggests that we may need to more aggressively manage peak VOC pain. On the other hand, median pain intensity at discharge was 0 , suggesting that perhaps patients are being kept in hospital too long. We need to strike a balance between managing peak pain intensity aggressively and monitoring closely, to ensure patients are discharged at an appropriate time for continued home management.

\section{Clinical pain outcomes}

Pain intensity assessment: The pain experience of this sample differs from that reported in the literature. Other studies reported a characteristic pattern of peak pain, with a significant decline in pain only during a resolving phase four to five days after admission $(24,25)$. Jacob and Mueller (11) found that least and worst pain remained unchanged and severe in intensity throughout the hospital stay. However, peak pain intensity in this study was shown to decline greatly during the first two days of admission though it did remain moderate to severe throughout hospitalization, and least pain was consistently low to moderate. This may be partially attributed to the difference in the mean age of patients in the previous study compared with ours (13.6 \pm 4.3 versus $10.0 \pm 5.3$ years), because it has been demonstrated that adolescents with SCD often experience longer and more intense pain episodes than younger children. However, it is also 
important to note that we found significant differences among patients in their pain score trajectories over time (ie, patients' scores across time may have decreased significantly or only a little, stayed the same, or even increased), demonstrating the unpredictability of pain during a VOC.

\section{Next steps}

Several studies have reported that implementing day hospitals (DH) for SCD patients can provide effective and timely management of VOCs, while also saving costs (26-31). For example, Raphael et al $(26,27)$ found that the use of DH for patients with SCD reduced average length of stay by $39 \%$. Benjamin et al (31) reported similar reductions in length of stay, as well as a $40 \%$ decrease in combined $\mathrm{ED} / \mathrm{DH}$ admissions one year postimplementation. Overcoming undertreatment of pain was also possible, through titration of medications and flexibility in choice of drugs. Thus, implementing SCD DH may address the problems we report here on pain assessment and management practices, especially in the ED setting. Partially informed by the results obtained in the present audit, the hospital at which our study was conducted opened an SCD DH in 2011. The DH addresses several areas the present audit suggested targeting for improvement, including improved support and education for families and patients, aggressive management of peak pain and a team that is well informed about pain documentation practices. We plan to conduct an audit similar to the present one invovling the $\mathrm{DH}$. The results will be compared with the present study to evaluate the benefit of the $\mathrm{DH}$.

\section{Limitations}

There are several limitations to the present study. First, we used a convenience sample - most charts were extracted in chronological order but a few were randomly selected from later in the year to attempt to obtain a sampling of all seasons of the year. This sampling method limits the generalizability of the findings. Second, because it was retrospective in nature, the completeness of available patient chart information was a limiting factor. It is unclear whether pain assessment was not performed or that management strategies were not provided, or whether they were inadequately recorded. Knowledge of this information could guide recommendations for either improved pain management or improved recording practices. As well, when evaluating adherence to hospital pain assessment guidelines, we only report whether standards were met on a daily basis; thus, it is impossible to distinguish whether standards were adequately met for most,

\section{REFERENCES}

1. Hassell KL. Population estimates of sickle cell disease in the U.S. Am J Prev Med 2010;38:S512-21.

2. Yang Y, Sha A, Watson M, et al. Comparison of costs to the health sector of comprehensive and episodic health care for sickle cell disease patients. Public Health Rep 1997;110:80-6.

3. Shapiro BS, Cohen DE, Howe CJ. Patient-controlled analgesia for sickle-cell-related pain. J Pain Symptom Manage 1993;8:22-8.

4. Brandow AM, Brousseau DC, Pajewski NM, et al. Vaso-occlusive painful events in sickle cell disease: Impact on child well-being. Pediatr Blood Cancer 2010;54:92-7.

5. Gil FM, Sleeper LA, Weiner SJ, et al. Clinical events in the first decade in a cohort of infants with sickle cell disease. Blood 1995;86:776-83.

6. Fosal MB, Wojner-Alexandrov AW. Events of hospitalization among children with sickle cell disease. J Pediatr Nurs 2007;22:342-6.

7. Benjamin LJ, Dampier CD, Jacox AK, et al. Guideline for the Management of Acute and Chronic Pain in Sickle Cell Disease. Glenview: American Pain Society, 1999.

8. Rees D. Guidelines of the management of the acute painful crisis in sickle cell disease. Br J Haematol 2003;120:744-52.

9. Beyer JE. Judging the effectiveness of analgesia for children and adolescents during vaso-occlusive episodes of sickle cell disease. J Pain Symptom Manage 2000;19:63-72.

10. Jacob E, Miaskowski C, Savedra M, et al. Quantification of analgesic use in children with sickle cell disease. Clin J Pain 2007;23:8-14. part or none of the day. Additionally, hospital guidelines have changed since the end of the study period; as of July 2010, codeine is no longer in the hospital formulary of drugs. Thus, the overuse of codeine (rather than using alternatives such as morphine or hydromorphone) reported in the present study is no longer a problem in clinical practice at our institution, although these findings may be applicable to other institutions. Finally, our data were from a single hospital, which limits the generalizability of findings. However, the present study highlights several issues that may be prevalent in other institutions and, thus, illustrates the need for and provides a model for auditing and benchmarking practices in patients with SCD.

\section{CONCLUSIONS}

Children with SCD experience painful VOC with lengthy periods of severe peak pain. To better manage the VOC and improve clinical outcomes (pain intensity, length of stay), there are three broad pain process areas to target for improvement. An integral part of pain management is assessment; therefore, pain must be assessed and documented using valid tools, and according to clinical practice guidelines. Second, pain must be managed aggressively because children currently continue to receive suboptimal analgesic doses and do not receive balanced multimodal treatments. Finally, improved education and support of pain management at home could prevent children with VOC from needing hospitalization. Further studies are needed to determine whether there are optimal combinations of pain management strategies that prevent hospital admission or reduce length of stay. Future research should also evaluate the effectiveness of suggested interventions such as SCD DH, and patient, family and health care provider education programs. Finally, the present study demonstrates that other institutions may benefit from similar audits to benchmark practice and determine institution-specific improvements.

ACKNOWLEDGEMENTS: Dr Stinson's work was supported by a Canadian Institutes for Health Research (CIHR) Post-Doctoral Fellowship. Ms Vijenthira was supported by a CIHR Summer Studentship. The authors thank Isabella Mak, Jessica Holt, Michael Corbo and Saife Hajee for assistance with data extraction.

DISCLOSURES: The authors have no financial disclosures or conflicts of interest to declare.

11. Jacob E, Mueller B. Pain and experience of children with sickle cell disease who had prolonged hospitalizations for acute painful episodes. Pain Med 2008;9:13-21.

12. Jacob E, Miaskowski C, Savedra M, et al. Management of vasoocclusive pain in children with sickle cell disease. J Pediatr Hematol Oncol 2003;25:307-11.

13. Jacob E, Miaskowski C, Savedra M, et al. Changes in intensity, location, and quality of vaso-occlusive pain in children with sickle cell disease. Pain 2003;102:187-93.

14. Taylor EM, Boyer K, Campbell FA. Pain in hospitalized children: A prospective cross-sectional survey of pain prevalence, intensity, assessment and management in a Canadian pediatric teaching hospital. Pain Res Manag 2008;13:25-32.

15. Weingarten KA, Stinson J, Carbajal R, et al. A single day audit of pain assessment and management practices in a pediatric hospital. Pediatric Academic Society 2008. Abst.

16. The Hospital for Sick Children Clinical Practice Guidelines. Pain assessment. Toronto, Ontario: The Hospital for Sick Children, 2010.

17. Acute Pain Service Dosing Handbook. Toronto, Ontario: The Hospital for Sick Children, 2009.

18. Steedman SM, Middaugh SJ, Kee WG, et al. Chronic-pain medications: Equivalence levels and method of quantifying usage. Clin J Pain 1992;8:204-14.

19. Drug Handbook and Formulary. Toronto, Ontario: The Hospital for Sick Children, 2009. 
20. SPSS for Windows. SPSS Version 17.0. Chicago: SPSS Inc, 2008.

21. Drendel AL, Brousseau DC, Gorelick MH. Pain assessment for pediatric patients in the emergency department. Pediatrics 2006;117:1511-8.

22. Kuan SC, Collins NC, Ryan JM, et al. Treating pain in the emergency department. Eur J Emerg Med 2010;17:52-5.

23. Dampier C, Ely E, Brodecki D, et al. Home management of pain in sickle cell disease: A daily diary study in children and adolescents. J Pediatr Hematol Oncol 2002;24:643-7.

24. Beyer JE, Simmons LE, Woods GM, et al. A chronology of pain and comfort in children with sickle cell disease. Arch Pediatr Adolesc Med 1999;153:913-20.

25. Jacob E, Beyer JE, Miakowski C, et al. Are there phases to the vaso-occlusive painful episode in sickle cell disease? J Pain Symptom Manage 2005;29:392-400.

26. Raphael JL, Kamdar A, Wang T, et al. Day hospital versus inpatient management of uncomplicated vaso-occlusive crises in children with sickle cell disease. Pediatr Blood Cancer 2008;51:398-401.
27. Raphael JL, Kamdar A, Beavers B, et al. Treatment of uncomplicated vaso-occlusive crises in children with sickle cell disease in a day hospital. Pediatr Blood Cancer 2008;51:82-5.

28. Adewoye AH, Nolan V, McMahon L, et al. Effectiveness of a dedicated day hospital for management of acute sickle cell pain. Haematologica 2007;92:854.

29. Ware MA, Hambleton I, Ochaya I, et al. Day-care management of sickle cell painful crisis in Jamaica: A model applicable elsewhere? Br J Haematol 1999;104:93-6.

30. Wright J, Bareford D, Wright C, et al. Day case management of sickle pain: 3 years experience in a UK sickle cell unit. Br J Haematol 2004;126:878-80.

31. Benjamin LJ, Swinson GI, Nagel RL. Sickle cell anemia day hospital: An approach for the management of uncomplicated painful crises. Blood 2000;95:1130-7. 


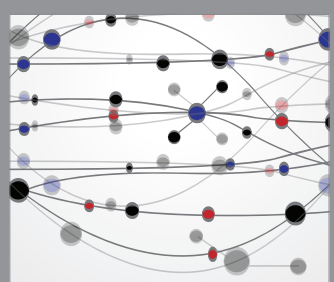

The Scientific World Journal
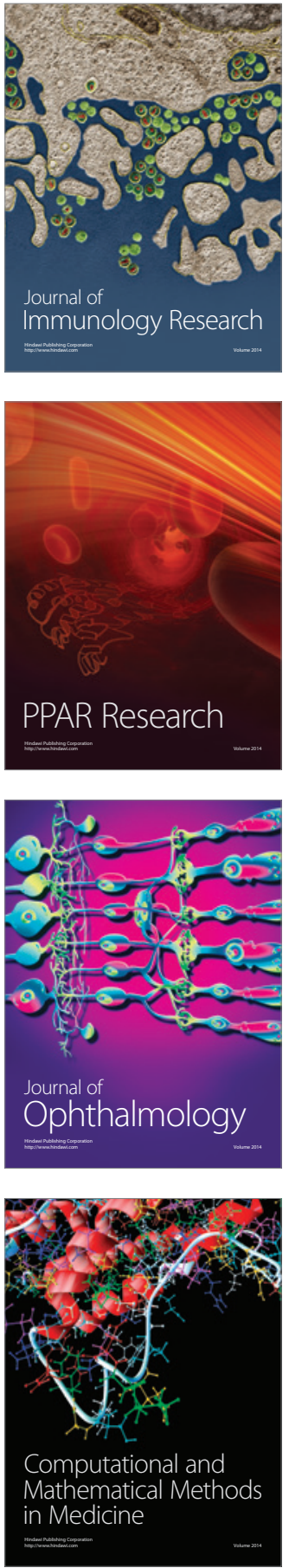

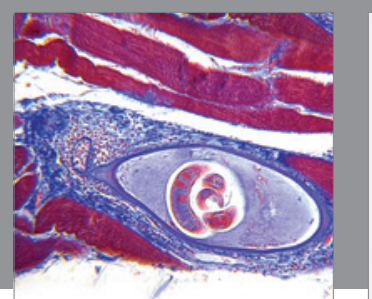

Gastroenterology Research and Practice

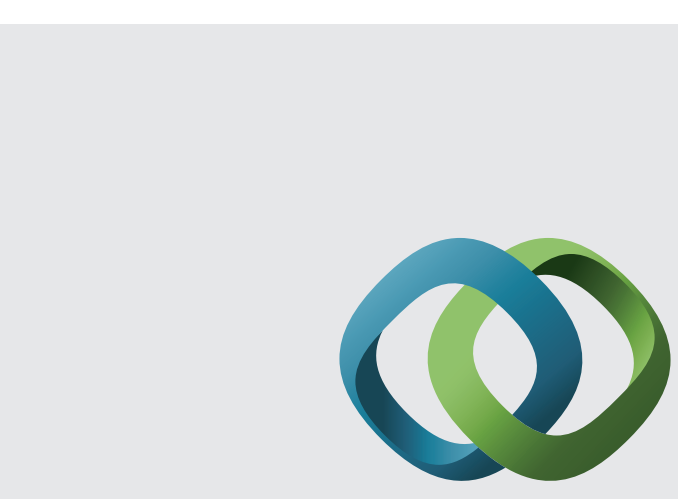

\section{Hindawi}

Submit your manuscripts at

http://www.hindawi.com
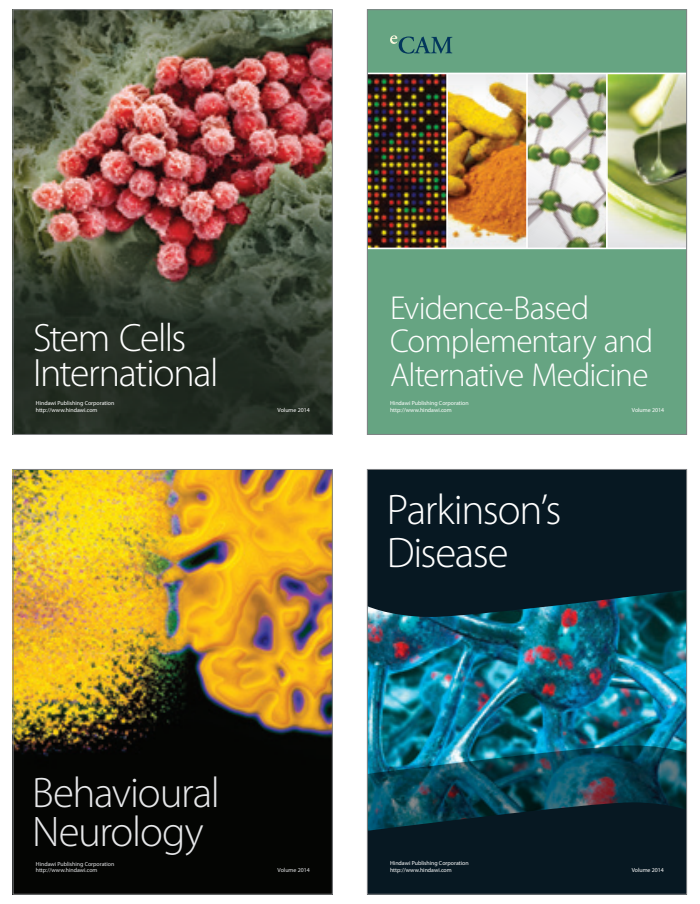
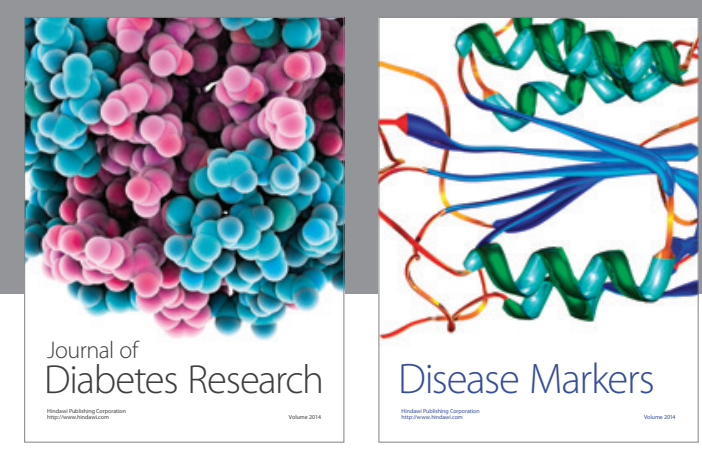

Disease Markers
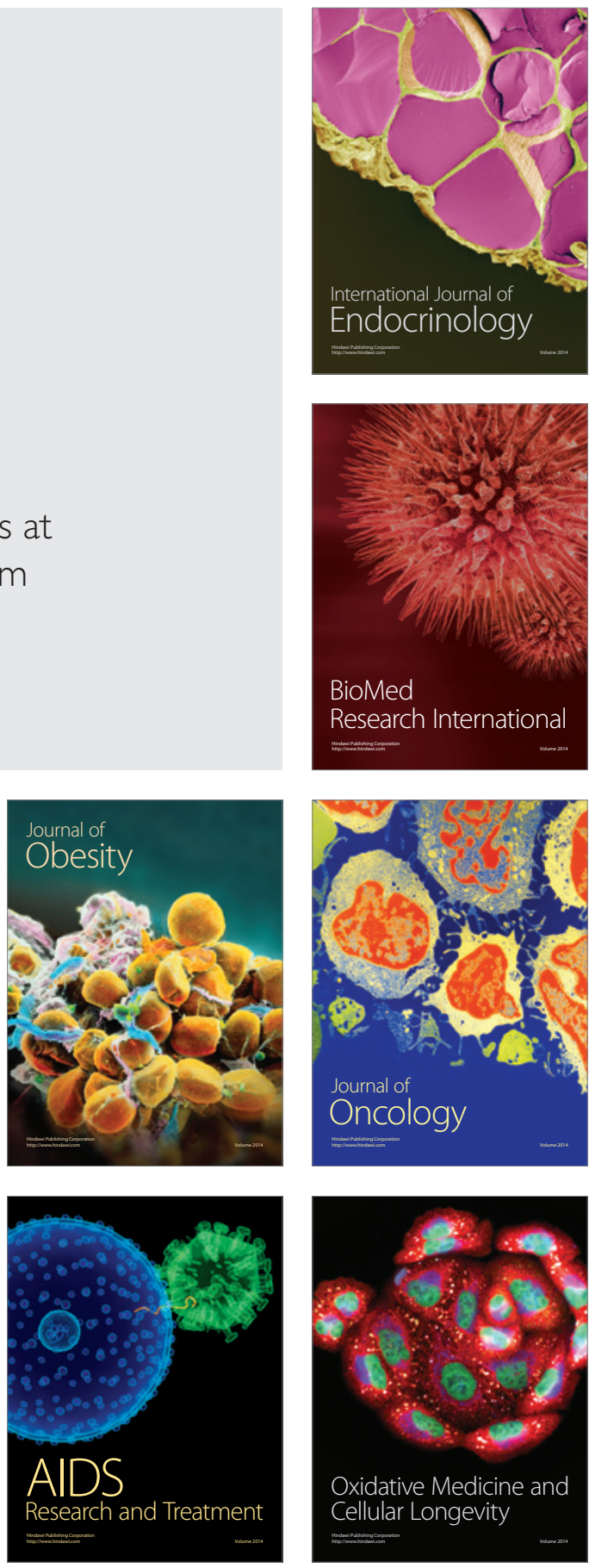